\title{
The Importance of Continental Evaporation for Precipitation in Colombia: A Baseline Combining Observations from Stable Isotopes and Modeling Moisture Trajectories
}

\author{
Maritza Escobar ${ }^{1}$, Isabel Hoyos ${ }^{2}$, Isabel Hoyos ${ }^{1}$, and Juan Camilo Villegas ${ }^{1}$ \\ ${ }^{1}$ Universidad de Antioquia \\ ${ }^{2}$ Universidad del Quindío
}

September 25, 2021

\begin{abstract}
The hydroclimatology of Northern South America responds to strongly-coupled dynamics of oceanic and terrestrial surfaceatmosphere exchange, as moisture evaporated from these sources interact to produce continental rainfall. However, the relative contributions of these two source types through the annual cycle have been described only in modeling studies, with no observational tools used to corroborate these predictions. The use of isotopic techniques to study moisture sources has been common in assessing changes in the water cycle and in climate dynamics, as isotopes allow tracking the connection between evaporation, transpiration, and precipitation, as well as the influence of large scale hydroclimatic phenomena, such as the seasonal Inter Tropical Convergence Zone migration. We characterize the isotopic composition of moisture sources becoming precipitation in the Andes and Caribbean regions of Colombia, using stable isotopes data $(\delta 18 \mathrm{O}, \delta 2 \mathrm{H})$ from the Global Network of Isotopes in Precipitation (1971-2016) and contrasting it with moisture trajectory tracking from the FLEXPART model, using input from ERA-Interim reanalysis to compute the relative contribution of oceanic and terrestrial sources through the annual cycle. Our results indicate that most precipitation in the region comes from terrestrial sources including recycling ( $>30 \%$ for all months), Orinoco (up to $28 \%$ monthly for April), and the northern Amazon (up to $17 \%$ monthly for June, July, and August); followed by oceanic sources including the Tropical South Pacific (up to $30 \%$ monthly in October, November, December) and Tropical North Atlantic (up to $30 \%$ monthly for January). These outcomes highlight the utility of combining stable isotopes in precipitation and modeling techniques to discriminate terrestrial and oceanic sources of precipitation. Further, our results highlight the need to assess the hydrological consequences of land cover change in South America, particularly in a country like Colombia where water, food and energy security all depend directly on precipitation. .
\end{abstract}

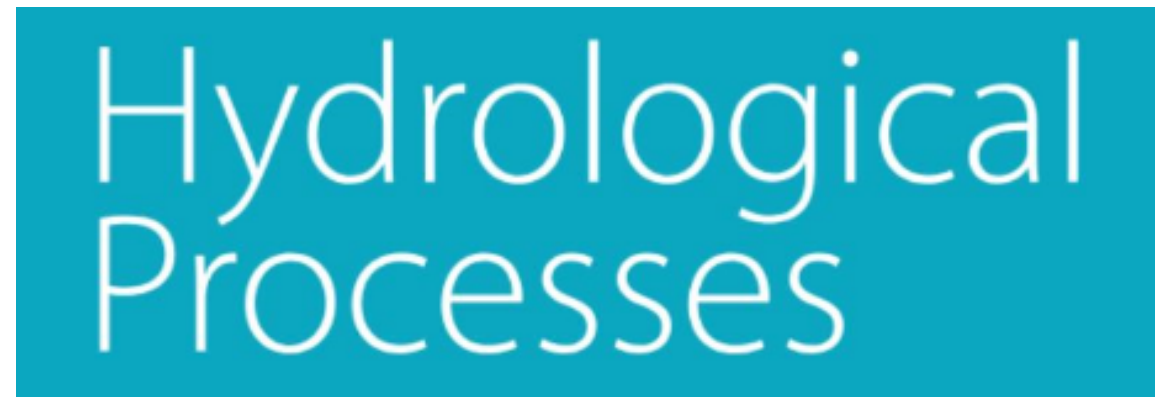

\section{INTRODUCTION}


The hydrological cycle explains water distribution and its availability across the globe. Processes such as evaporation, transpiration, and precipitation connect the terrestrial and atmospheric components of the hydrological cycle through water and energy exchange. Atmospheric circulation allows regional-to-global water redistribution, establishing teleconnections between remote areas. These teleconnections are vital for the sustainability of ecosystems and biodiversity as well as for water security, and socioeconomic development (Wagener et al., 2010; Martinez \& Dominguez, 2014; Swann, Longo, Knox, Lee, \& Moorcroft, 2015; Molina, Salazar, Martínez, Villegas, \& Arias, 2019). Understanding moisture origin and the mechanisms driving atmospheric transport is key for defining the interdependence of a territory with its surroundings, and also for the definition of proper spatio-temporal dynamics that determine regional atmospheric processes.

The conventional methods to identify moisture source regions, and to estimate the proportion of incoming atmospheric moisture associated with each source include i) analytical or box models, ii) numerical water vapor tracers, and iii) physical water vapor tracers (Durán-Quesada, Gimeno, Amador, \& Nieto, 2010). The first two are theoretical-computational models based on the Eulerian and Lagrangian notion of trajectory, respectively. These models often use input information from gauge stations and reanalysis data (Wang et al., 2004; Fuka et al., 2014; Liu et al., 2020). The third method is based on physical water vapor tracers in the isotopic composition of precipitation. The interpretation of moisture tracers is useful to infer the sources and the processes inducing fractionation in water isotopic composition throughout the movement of air masses (Simpson \& Herczeg, 1991; Martinelli, Victoria, Sternberg, Ribeiro, \& Moreira, 1996; Clark \& Fritz, 1999). More specifically, the isotopic composition of rainwater allows the interpretation of prevailing meteorological conditions in the formation of air masses (temperature, humidity, wind speed) and the origin of moisture (evaporation and/or transpiration) (Gat \& Carmi, 1970; Clark \& Fritz, 1999; Duran-Quesada et al., 2010; Gimeno, Drumond, Nieto, Trigo, \& Stohl, 2010; Van der Ent, Savenije, Schaefli, \& Steele-Dunne, 2010; Gimeno et al., 2012). The study of moisture sources through stable isotopes has been widely used in understanding long-term changes in the water cycle and the dynamics of climate (Gat \& Carmi, 1970; Salati, 1979; Gat \& Gonfiantini, 1981; Clark \& Fritz, 1999; Aggarwal, Froehlich, \& Gat, 2005; Van der Ent et al., 2010; Gimeno et al., 2012; Négrel, Petelet-Giraud, \& Millot, 2016; Sánchez-Murillo et al., 2016; Alexandre, 2020). However, the lack of isotopic data in many locations around the world is still a disadvantage for proper long-term analyses (Benjamin et al., 2005).

A current challenge for land and water resource managers is the definition and understanding of the potential implications of environmental change on the availability of water resources (Newman et al., 2006; Gain et al., 2020; Rivadeneira et al., 2020). This challenge has been generally addressed with local-scale management plans and strategies. However, in a region like Northern South America (particularly in Colombia), water, food and energy security (which largely supports the country's economy) depend, almost exclusively, on surface water, which in turn is associated with short-term rainfall generation processes (Álvarez-Villa, Vélez, \& Poveda, 2011; Díaz, Saurral, \& Vera, 2020; Mesa, Urrea, \& Ochoa, 2021). In addition, Colombia is one of the most biodiverse regions in the world (Myers, Mittermeier, Mittermeier, Da Fonseca, \& Kent, 2000; Churchill, 2009; Bruijnzeel, Scatena, \& Hamilton, 2011; Herzog \& Kattan, 2011; Ehrendorfer, 2013; Hutter, Lambert, \& Wiens, 2017; Hoorn, Perrigo, \& Antonelli, 2018; Bax \& Francesconi, 2019). The connection with the Pacific and Atlantic oceans, the Amazon-Andes interactions, and the orographic barrier of the regional Andes are the major drivers of atmospheric circulation and ecological diversity in the country (Sakamoto, 2011; Hoyos, 2017; Poveda, Jaramillo, \& Vallejo, 2014; Espinoza et al., 2020). For biodiversity conservation, ecosystem health, and socioeconomic development, the availability of water is an important basis that depends on hydrologic functioning (Pringle, 2001). Therefore, understanding the origin and dynamics of moisture that becomes rainfall in the two most populated regions of the country is fundamental to maintaining water security. Yet, these analyses have only been performed with models that, to date, have not been contrasted with actual field measurements such as those from environmental tracers.

In this study, we explore the hydroclimatic features underlying the composition of Colombian atmospheric moisture by establishing the isotopic baseline for the regional precipitation on a seasonal time scale. We include data from 33 stations distributed along the inter-Andean mountain region and the Caribbean region in Colombia, available in the Global Network of Isotopes in Precipitation (GNIP) project. We analyze the 
monthly variation of $\delta^{18} \mathrm{O}$ and $\delta^{2} \mathrm{H}$ values, and the spatio-temporal reconstruction of D-excess during 19712016. Comparing the Local Meteoric Water Line (LMWL) with the Global Meteoric Water Line (GMWL) provides criteria of depletion or enrichment of hydrogen and oxygen isotopic composition of precipitation that, in turn, allow the identification of the oceanic or terrestrial origin of air-water masses that effectively precipitates over the target area. We use the results from the Lagrangian FLEXPART model to contrast the information inferred from isotopic composition with the regional moisture contributions structure based on the air masses trajectories, providing a more comprehensive understanding of moisture sources to the country and the potential implications of alterations in these dynamics associated with land use and vegetation cover change.

\section{DATA AND METHODS}

\subsection{Study area}

This research focuses on atmospheric moisture transport over central and northern Colombia. The target region (Fig. 1) corresponds to the largest hydrological system in the country, draining the Andes Mountain chain towards the Caribbean Sea and encompasses two regions with marked orographic differences: the Magdalena-Cauca River basin (Andean), and the Caribbean regions. Due to their location, the oceanic influences in the regional climate are characterized by the transport of moisture from the Tropical and Subtropical Atlantic and Pacific Oceans, and terrestrial sources from the Orinoco and Amazon basins, as well as local recycling (Hoyos, 2017; Hoyos and Rodriguez, 2020).

\section{[Insert Figure 1]}

The Magdalena-Cauca River basin system is the major Andean catchment in the country. It is characterized by a complex orography defined by the division of the Andes into three branches, i) the western branch crosses Colombia from south to north with approximately $1200 \mathrm{~km}$ in length, parallel to the pacific coast, ii) the central branch between the Cauca and Magdalena River valleys and iii) the eastern branch with an extension of approximately $1500 \mathrm{~km}$ and heights up to 4500 meters above sea level, towards the Amazon and Orinoco basins. The Magdalena River flows in a Valley between the Eastern and central branches, and the Cauca flows between the Central and Western branches. Their confluence occurs at the lowlands that mark the transition to the Caribbean region. The interaction between the large-scale circulation systems, the trade winds, and the orographic systems results in differentiated climatic regions over the territory.

The rainiest areas generally occur on the eastern slopes of the eastern cordillera and the western slopes of the western cordillera, while rainfall is lower (and more variable) in the inter-Andean valleys (Snow, 1975; Hoyos, Baquero-Bernal, \& Hagemann, 2013). Likewise, the Amazon region exports water vapor to the Andean and inter-Andean zones generating high rainfall intensity, due to the ascent of trade winds and the orographic effect of the Andes (Espinoza et al., 2020). The distribution of precipitation in this region has significant spatial and temporal variability (Poveda, Waylen, \& Pulwarty, 2006; Hoyos et al., 2013; Poveda et al., 2014; Espinoza et al., 2020). The most influential seasonal event in the region is the migration of ITCZ that determines the annual distribution of rainfall, characterized by a bimodal regime with two wet seasons between March to May and September to November (Giannini, Kushnir, \& Cane, 2000; Alvarez-Villa et al., 2011; Espinoza et al., 2020) and its interaction with the Atlantic and the Pacific Ocean, the moisture contribution from the Caribbean Sea, and the Amazon and Orinoco basins (Hoyos, 2017).

The Caribbean region, located in the northernmost portion of Colombia (and South America), is low and flat in the north (except for the occurrence of the Sierra Nevada de Santa Marta complex, a coastline isolated mountain with a height of $5.7 \mathrm{~km}$ that influences local atmospheric circulation in the North), in contrast with the southern part of this zone, which is framed by the foothills of the Andes Mountain range. The annual cycle of rainfall in this zone has a different pattern from the Andes: a dry period from November to April and a rainy period between May to October, explained by the ITCZ migration, the occurrence of synoptic disturbances associated with the Tropical Easterly Waves (TEWs), and the Caribbean Low-Level Jet (Poveda et al., 2006; Arias, Martínez, \& Vieira, 2015; Cárdenas, Arias, \& Vieira, 2017). 


\subsection{Regional moisture contributions from FLEXPART}

We set the regional sources of atmospheric moisture (Fig. 2), based on Hoyos et al. (2018), as follows: Tropical North Pacific (TNP), Tropical South Pacific (TSP), Subtropical North Atlantic (STNA), Tropical North Atlantic (TNA), Tropical Atlantic (TA), Tropical South Atlantic (TSA), Caribbean Sea (CARS), Northern South America (NOSA), Orinoco Basin (ORIC), Northern Amazon Basin (NAMZ), and Southern Amazon Basin (SAMZ). In Hoyos et al. (2018), these zones were determined by the best agreement among the Dynamical Recycling Model (DRM), the Quasi-Isentropic Model (QIBT), and the Flexible Particle Dispersion Model (FLEXPART).

\section{[Insert Figure 2]}

The FLEXPART is a 3D Lagrangian dispersion model that accounts for the net loss (or gain) of specific humidity, $q$, along with a large number of backward/forward trajectories between source and target areas (Stohl \& James, 2005, 2004; Gimeno et al., 2012; Sodeman et al., 2015). The moisture contribution from a source area is estimated by accounting for the vertically-integrated long-term balance of precipitation $\mathrm{P}$ and evaporation $\mathrm{E}$ along the trajectories for a large number of computational particles (2 million). Net $\mathrm{E}$ $\mathrm{P}<0$ represents a loss of moisture (precipitation exceeds evaporation), and $\mathrm{E}-\mathrm{P}>0$ represents a gain of moisture (evaporation exceeds precipitation) (Stohl \& James, 2005, 2004). The diagnostic precipitation (P) corresponds to the climatological sum of $|\mathrm{E}-\mathrm{P}<0|$ over the entire period.

Here, we estimate the composition of moisture contributions using the experiment developed by Hoyos et al., (2018). However, we calculate the seasonal values considering the optimal transport day (that is, the day when the moisture transference is maximum) instead of the 10-day global mean lifetime of water vapor in the atmosphere (Numaguti, 1999; Gimeno, Nieto, Drumond, Castillo, \& Trigo, 2013; Van der Ent \& Tuinenburg, 2017; Gimeno et al., 2021). This experimental design accounts for the fact that the time scale at which the regional atmospheric moisture is exchanged depends on the dynamic relationship between source and target regions (including not only distance but also the intensity of the advective processes and mechanisms that cause precipitation). We expect that, as the integration time of the moisture trajectories increases, the contribution of each source region correspondingly increases until reaching the maximum contribution value, after which moisture contribution shows a decreasing or asymptotic behavior (Hoyos et al., 2017; Nieto \& Gimeno, 2019). Setting integration times at the optimum allows us to avoid over (or under) estimations in the relative contributions of moisture sources. The period simulated 1980-2012, includes the availability period of rainwater isotope records.

\subsection{Physical Water Vapor Tracers}

We use a combination of isotopic indices derived from local and global meteoric water lines to confirm moisture sources to the study region.

\subsubsection{Local Meteoric Water Line}

The Global Meteoric Water Line (GMWL) [Craig (1961)] provides the relationship between the global isotopic contents of $\delta^{18} \mathrm{O}$ and $\delta^{2} \mathrm{H}$, referred to the Vienna Standard Mean Ocean Water (VSMOV), as:

$\delta^{2} \mathrm{H}=8 \delta^{18} \mathrm{O}+10$

At the local scale, this relationship is represented by the Local Meteoric Water Line (LMWL) which can be used to determine how (i) the spatial variability of the linear statistical relationship between isotopic ratios, and (ii) the variation in slope that provides information about the seasonal climatology of a particular site (Rozanski, Araguás-Araguás, \& Gonfiantini, 1993; Putman, Fiorella, Bowen, \& Cai, 2019). Therefore, the extent (and direction) of the deviation of the LMWL from the GMWL is an indicator of the thermodynamic state of vapor formation processes, as well as the strengthening/weakening of processes or mechanisms involved in the atmospheric vapor transport. We constructed the LMWL for the study area, based on the linear regression of the monthly average of $\delta^{18} \mathrm{O}$ and $\delta^{2} \mathrm{H}$ isotope composition for the period between 1971 and 2016. Data of isotope composition of local precipitation were obtained from the Global Network of 
Isotopes in Precipitation (GNIP) project (IAEA, 2020). We included up to as many as 33 sampling points (shown in Fig 1.)

The deviation of LMWL from GMWL explains the depletion/enrichment of isotopic composition of precipitation concerning the GMWL and how it can be interpreted in terms of processes and water vapor formation conditions that air masses suffer in their evolution before becoming precipitation. This information is useful to infer the terrestrial or oceanic origin of water vapor. Pairs of $\delta^{18} \mathrm{O}$ and $\delta^{2} \mathrm{H}$ in the LMWL result from the interaction of fractionation generated in the advance into the continent of moisture flow and meteorological conditions at the site (Dansgaard,1964). Since the GMWL is used as the 'expected' equilibrium relationship (Putman et al., 2019), the LWML is often evaluated in the context of its deviation from the GMWL, in terms of the variability of $\delta^{18} \mathrm{O}$ and $\delta^{2} \mathrm{H}$ pairs. Pairs of $\delta^{18} \mathrm{O}$ and $\delta^{2} \mathrm{H}$ in the LMWL bring information of the history of fractionation of water in the air mass due to phase changes such as evaporation, condensation, and transpiration, as well as variations due to meridional and altitudinal changes that are arising from the progressive rainout of heavy isotopes during the evolution of a precipitating air mass (Rayleigh distillation, Gat, 1996). Depletion or enrichment of isotopes in precipitation is expressed by the deviation from the VSMOW. In general, expected values from terrestrial regions exhibit depletion in isotopic composition due to Rayleigh distillation, and expected oceanic values from cold sources (for instance the Pacific Ocean or the South Atlantic Ocean for the study area) are more depleted than the isotopic composition originated from warmer sources (for example the Tropical Atlantic).

We compiled the main findings from (Putman et al., 2019) and (Clark \& Fritz, 2013) in order to produce a conceptual scheme for the interpretation of moisture origin based on the comparison between the relative position of isotopic observations in precipitation and the GMLW (Fig. 3). When $\delta^{18} \mathrm{O}$ and $\delta^{2} \mathrm{H}$ pairs are located in the upper-right (lower-left) portion of the line (Fig. 3), indicates that moisture was originated in warmer (colder) regions, low (high) altitude, low (high) latitude, and coastal (terrestrial) zones (Clark \& Fritz, 2013). Similarly, terrestrial (and water) sources in this scheme are located above (below) the GMWL (Putman et al., 2019).

[Insert Figure 3]

\subsubsection{D-excess}

Deuterium excess (hereafter D-excess, $d$ ) is understood as a measure of the deviation of the LMWL from the GMWL. D-excess is also a key parameter to infer the origin of atmospheric vapor regarding the evaporation conditions in the region source of precipitation (Petit, White, Young, Jouzel, \& Korotkevich, 1991; Froehlich, Gibson, \& Aggarwal, 2002; Froehlich et al., 2008). D-excess follows the relationship:

$d=\delta^{2} \mathrm{H}-8 \delta^{18} \mathrm{O} .(2)$

Higher values of $d$ refer to moisture originated under conditions of lower relative humidity, where the kinetic fractionation is more pronounced. Lower values of $d$ correspond to air masses where the fractionation was close to equilibrium (Clark \& Fritz, 1999). However, some secondary processes can change the initial value. For instance, $d$ is an indicator of moisture recycling as evaporation from the land surface to the atmosphere increases its value (Froehlich et al., 2002; Froehlich et al., 2008). Spatial reconstruction of $d$ values was developed through coKriging interpolation, using precipitation and temperature as auxiliary variables for improving the estimations over areas where there is no sampling data. The spatial resolution of D-excess value in the study zone is $1^{\circ} \times 1^{\circ}$ degree.

\section{RESULTS}

\subsection{Oceanic and continental contributions to precipitation}

Our results show that the spatial and temporal scales at which each source region influences precipitation in the study area vary and, importantly, vary from the mean 10-day residence time commonly used as integration time (Table 1). For instance, while the oceanic contribution from the Pacific reaches the Andean region in 2 to 7 days (TSP and TNP), moisture originated in the Atlantic Ocean takes longer than 10 days 
to become precipitation (TA, TSA, STNA). Atlantic sources have a time scale for the optimal transport day in the 10-day global mean lifetime of water vapor, except for CARS (that is between 4 and 6 days for the Andean region and between 3 and 4 for the Caribbean region). Transport time scales for Pacific sources have differentiated features. TNP spends 2 days reaching the optimum transport time while TSP varies from 2 to 7 days for the Andean region, and from 8 to 9 for the Caribbean region. ORIC is the second largest terrestrial source with a time scale of moisture transport of around 4 days. The time transport from NAMZ to the Andean region is between 6 to 7 days and to the Caribbean region is 8 days. As expected, the largest spatial extents correspond to more distant source regions while the closest source regions have the lowest spatial extents and integration times. (Appendix A includes detailed information about climatological monthly diagnostic precipitation for different integration times).

[Insert Table 1]

We estimated the effective amount of precipitation from each source based on the percentage of diagnostic precipitation accounted for FLEXPART. Observational data from 1506 gauge stations along the entire region provided by the IDEAM (Colombia's National hydroclimatic agency) were included in order to regionally validate the model results (Fig. 4). In general, the annual mean moisture contribution from the Atlantic (Pacific) ocean is larger in the Caribbean (Andean) region than for the Andean (Caribbean) region (Figure 5 and 6). The main atmospheric Atlantic sources for both target regions are TNA, TA, and CARS (Fig 5a, 5d). In the Andean region, TSP contributions are larger than TNP (Fig. 5b), while both Pacific sources have similar contributions for the Caribbean region (Fig. 5e). Terrestrial recycling accounts for more than $50 \%$ of the total (59.40\% to the Andean and $56.74 \%$ to the Caribbean; Fig. 5c, 5 f respectively and Fig. 6). The local atmospheric moisture from NOSA reaches the maximum contribution in 1 day. Overall, NOSA is the largest contributor among the terrestrial and oceanic sources, with an annual contribution of $37.98 \%$ (32.10\%) for the Caribbean (the Andean) region. For the Caribbean (Andean) region, the atmospheric moisture from ORIC is comparable to the total contribution from the Pacific (Atlantic) Ocean. For both target areas, the contribution from the TNA (TSP), is the largest Atlantic (Pacific) source. As expected, moisture coming from the Amazon basin is higher for northern Amazon (NAMZ), and the contribution is greater in the Andean compared to the Caribbean region (Fig. 5c, 5f), but its relative importance is, on average, smaller than the other two terrestrial sources.

\section{[Insert Figure 4]}

[Insert Figure 5]

Moisture contributions to both regions have a marked seasonal behavior, with the relative contribution of oceanic and terrestrial sources varying through the year. For all months, terrestrial sources dominate moisture contributions in both regions (Fig. 6). The predominant oceanic moisture source for the first season of the year (JFM) is the Atlantic Ocean, with total monthly contributions greater than $26 \%$ for the Andean region, and greater than $41 \%$ for the Caribbean region (Fig. 6). More specifically, the TNA region has the largest contributions, with more than $17 \%$ for the Andean region (Fig. 5a) and more than $27 \%$ per month for the Caribbean region (Fig. 5d). In the Andean region, the Pacific Ocean is the most predominant oceanic moisture source From May to December, with the contributions are over $36 \%$ for the months SOND (Fig. 6a). Particularly the TSP is the major moisture contributor to the Andean region exceeding $33 \%$ per month in November (Fig. 5b). Between May and October, the Caribbean region receives moisture predominantly from the Pacific Ocean (Fig. 6b), intensifying these contributions in October - November as the ITCZ stays in the northern hemisphere over the Atlantic and eastern Pacific.

\section{[Insert Figure 6]}

\subsection{Local Meteoric Water Line and hydroclimatic mechanisms}

The resulting LMWLs (Fig. 7) follow the expected trends based on depletion or enrichment of isotopic composition of $\delta^{18} \mathrm{O}$ and $\delta^{2} \mathrm{H}$ from theoretical considerations such as i) the orographic distillation that generates depletion of $\delta^{18} \mathrm{O}$ and $\delta^{2} \mathrm{H}$ values due to fractionation generated in the advance of moisture flow 
into the continent (Dansgaard, 1964; Rozanski et al., 1993; Clark \& Fritz, 1999; Mook, 2002; Aggarwal et al., 2005) ii) the proximity to atmospheric moisture sources (Guan, Zhang, Skrzypek, Sun, \& Xu, 2013); iii) the thermodynamic conditions of sources; iv) the mixing ratio of sources (Rindsberger, Magaritz, Carmi, \& Gilad, 1983; Rindsberger, Jaffe, Rahamim, \& Gat, 1990), and v) the amount effect that generates depletion in hydrogen and oxygen isotopes with the increase in monthly and annual precipitation of different places and with the intensity of the storms (Dansgaard, 1964).

\section{[Insert Figure 7]}

As in our Flexpart experiment, isotopic signals from the LMWLs also highlight the seasonal behavior of moisture sources for the two regions. More specifically, from December through February (Fig. 7a, 7b, $7 \mathrm{c})$, the Andean region exhibits a variation range of $\delta^{2} \mathrm{H}\left(\delta^{18} \mathrm{O}\right)$ that oscillates between -20 and -60 ( 5 and -9$) \delta^{2} \mathrm{H}$ oscillating between 0 and $-20 \delta^{18} \mathrm{O}$ between 0 and -5 these values represent the depletion of the heavy isotopes from coastal regions towards the continental interior (orographic distillation), while in the Caribbean, more depleted values represent the first condensate from marine moisture, indicative of meteorological conditions (such as relative humidity (72\%-79\%) and sea surface temperature $\left(25-28^{\circ} \mathrm{C}\right)$ ) from warm sources (Yurtsevert,1981; Rozanski et al. 1993), indicating the prevalence of oceanic sources (from the Atlantic ocean as indicated in our modeling results in Fig. 5). More specifically, the values of Oxygen and Hydrogen isotopes for both regions are similar to those proposed by Bowen (2003) for the TNA zone, and the FLEXPART results indicate that TNA was the most active source in this month for the study area $(>27 \%$, Fig. 5).

For the MAM season (Fig. 7d, 7e, 7f) in the Andean region, March represents the highest enrichment for this season, and April- May also exhibit an oscillation range for $\delta^{2} \mathrm{H}$ between 0 and -120 In the Caribbean region, March exhibits similar variations to DJF, while April-May observations vary along the LMWL with oscillations for $\delta^{2} \mathrm{H}$ between 0 and $-120 \delta^{18} \mathrm{O}$ between 0 and -20 terrestrial contribution for MAM corresponds to ORIC and NOSA sources (Fig. 5). For both regions, the footprint of these terrestrial contributions can be seen in the local LMWL located above the GMWL (Interpretation of Fig. 7, following guidelines on Fig. 3). Moisture from ORIC is located in the lower part of the figure, indicating its warm origin, and moisture from NOSA along the LMWL indicating sources with different temperatures. The large variation for both regions in April-May (Fig. 7d, Fig. 7e) responds to the mixing ratio effect. This spread in the isotopic composition of rainwater is produced by the mixing of different air masses that precipitate over Colombia. During this season, the study area is characterized by a complex combination of terrestrial and oceanic sources of moisture that contribute in different relative amounts to regional precipitation, associated with the dynamics of the ITCZ (Tables 2 and 3).

[Insert Table 2]

[Insert Table 3]

In JJA (Fig. 7g, 7h, 7i) the range of variations for $\delta^{2} \mathrm{H}$ in both regions oscillates between -20 and -80 VSMOW, and $\delta^{18} \mathrm{O}$ between -3 and -12 for the months of June-July (Fig. $7 \mathrm{~g}, 7 \mathrm{~h}$ ), observations are located in the middle of the variation range, coinciding with a dry period, and the contributions are a combination of terrestrial and oceanic moisture sources. For the Caribbean region, although not predominant, Atlantic sources are important (Fig. 6b), as indicated by enrichment observations of the LMWL. Similarly, terrestrial sources make their contributions from ORIC and NOSA (Fig. 5f), explaining the combination of terrestrial and oceanic sources. This is similar for the Andean region, which receives more contributions from terrestrial sources, followed by contributions from the Pacific Ocean (Fig. 6a). Particularly, for the Andean region the major contributions of terrestrial sources from NAMZ occurred during June $(>17 \%)$, and coincide with observations localized above of the GMWL and the lower part of LMWL due to the minor temperature of the NAMZ source.

In the SON season (Fig. 7j, 7k, 7l), the isotopic composition of precipitation shows more depleted values compared to the rest of the year, with a variation range for $\delta^{2} \mathrm{H}\left(\delta^{18} \mathrm{O}\right)$ between 0 and -120 (-2particular, October and November exhibit more depleted values, coinciding with an increment of the contribution from 
the cold Pacific Ocean (Fig. 6a). Also, this season corresponds to one of the two rainy seasons of the year, generated by the seasonal migration of the ITCZ, producing an increase of monthly precipitation and intensity of the storms, causing depletion in hydrogen and oxygen (amount effect). Likewise, the Caribbean zone receives predominant moisture sources from the Pacific Ocean, intensifying these contributions in October November due to the ITCZ staying in the northern hemisphere over the Atlantic and eastern Pacific.

\subsection{D-excess analysis}

Spatial variations of reconstructed D-excess are explained by theoretical considerations such as the effects of (i) distance or proximity to main moisture sources to the study areas (Guan et al., 2013); (ii) influence of oceanic or terrestrial sources (Aemisegger et al., 2014); (iii) depletion of the heavy isotopes from coastal regions toward the continental interiors (Gat \& Matsui,1991; Rozanski et al., 1993). Particularly, for the Andean region, the effects of oceanic or terrestrial sources and the depletion of heavy isotopes with distance to coastal regions are most evident (Upper left inserts in Fig. 7). This can be explained by the predominance of terrestrial sources depleted in $\delta^{18} \mathrm{O}$ and $\delta^{2} \mathrm{H}$ and the moisture transport route (e.g. from the Atlantic Ocean is larger than the Caribbean region causing major fractionations). For the Caribbean region, the proximity effect of main moisture sources to the target region is the most visible, given that, for this region, D-excess reconstruction shows predominant values close to the Caribbean Sea and the Atlantic Ocean, which agrees with previous reports from Terzer et al., (2021).

The seasonal variation of D-excess ranged from 7 to 15 its maximum in December/January (Fig. 7a, Fig 7b) and its minimum in June/July (Fig. 7g, Fig 7h). These changes are explained by air-sea conditions at distinct water vapor sources with specific D-excess values (Gat \& Gonfiantini, 1981) and modified by the mixing of inland water vapor from evapotranspiration with the air-mass (Gat, Joel, Bowser, \& Kendall, 1994) and by secondary evaporation (Frits, Drimmie, Frape, \& Oshea, 1987). In continental areas, the D-excess value is strongly controlled by temperature effects $\left(\delta^{18} \mathrm{O}\right.$ temperature coefficient increases to about 0.5 effect is evident in our interpolation with lower D-excess in the Caribbean region, and with higher temperatures and higher D-excess compared to the Andean region. In addition to the temperature effect, and considering the Rayleigh distillation phenomenon, $\delta^{18} \mathrm{O}$ values become lower when water vapor rains out at lower temperatures than oceanic sources (Dansgaard, 1964). There is an inverse relationship between $\delta^{18} \mathrm{O}$ and D-excess. As expected, our data in the Andean region shows this pattern, as its predominant moisture source is terrestrial, and is located away from the ocean. In the Andean region, the months that showed the highest values of D-excess correspond to the season with the low values of rainfall, with December and January being the months with the highest values of D-excess (Fig. 7a, Fig 7b), reaching up to 15in June and July (Fig. 7g, Fig 7h), due to the effect of secondary evaporation which can be especially large with small amounts of precipitation during hot dry months. April and May (the rainy season) report the lowest concentrations of deuterium excess, with a range variation between 8

\section{DISCUSSION}

Our results illustrate how physical water vapor tracers, such as stable isotopes in precipitation, allow tracking water sources in atmospheric circulation as they connect evaporation and precipitation, and their concentration indicates the meteorological conditions and the proximity to the main atmospheric moisture sources that originate precipitation, as expected. Although the use of stable isotopes in precipitation does not provide quantitative information about the amount of atmospheric moisture from the sources, it complements the information generated by models, such as in our FLEXPART experiment. More generally, this information has the potential to be integrated into atmospheric models to diagnose the percentage of moisture originated from the different sources (Wang et al., 2004; Fuka et al., 2014; Arias et al., 2015; Hoyos et al., 2018; Molina et al., 2019; Liu et al., 2020). Further, the combined use of physical tracers and models are particularly useful in regions with complex topographical and meteorological setups where model results can be highly uncertain.

The consideration of the optimal transport day (when the moisture transference is maximum), instead of the canonical 10-day mean lifetime of water vapor in the atmosphere, allowed us to improve the quantification 
of contributions from atmospheric moisture sources, highlighting the predominance of terrestrial sources all through the year. The natural scales of distance and time are closely linked to the regional structure of moisture source composition. Therefore, assumptions about uniformity or similarity to a global mean need to be revisited for each region, after consideration of the particular climatic and meteorological features. Conversely, the proper transport scales are footprints for each particular target area and include regional features like the mechanisms involved in the atmospheric moisture transport, orographic features, and distance between the target and source regions. The lack of knowledge of these scales could lead to over (or under) estimations of the degree of contribution from different sources and reduce the forecasting power of teleconnections.

Physical water vapor tracers help identify signals of the origin of incoming atmospheric moisture when the source is not influenced by mixing effects associated with different oceanic and terrestrial sources present in the majority of the seasonal analysis. Our results allowed us to identify oceanic sources connected with the seasonality migration of ITCZ, as well as terrestrial sources such as Amazon and Orinoco basins, that agree with meteorological criteria. Both of these observations are evident in the reconstruction of the D-excess, even when the spatial and temporal coverage of isotopic data is very low for Colombia. Although we have reconstructed a baseline for the isotopic structure of precipitation, it is also evident that a better sampling network is necessary to improve the monitoring network of stable isotopes to produce a more detailed analysis of the moisture transport processes, as they have done in more instrumented areas (Friedman, Smith, Gleason, Warden, \& Harris, 1992; Kendall \& Coplen, 2001; Bowen, Ehleringer, Chesson, Stange, \& Cerling, 2007; Bowen, Kennedy, Liu, \& Stalker, 2011).

Our results showed a multiannual moisture convergence average from terrestrial sources of $59 \%$ for the Andean region and for the Caribbean region of $56 \%$ (Figure 6), which is greater than previous estimations by our group (38\% in Hoyos et al., 2018). By using a combination of physical tracers and modeling, we confirm previous modeling results (Hoyos et al., 2018) that indicate how, in the study area, the contribution of terrestrial moisture sources to local precipitation is significant (always greater than $44 \%$ ), such that most ecosystems and water security for society and the economy may depend on the stability of major regional ecosystems such as the Orinoco plains (8\% - 28\% per month) and the Northern Amazon (17\% contribution). More importantly, our results highlight that most terrestrial moisture originates within the same region (NOSA), with contributions larger than $23 \%$ per month in some seasons and up to $40 \%$ per month in other seasons.

The fact that a significant proportion of rainfall comes from recycling (Fig. 6), highlights how precipitation and, more generally, water availability in the Andean and Caribbean regions of Colombia could potentially be altered by changes in vegetation and land cover, directly affecting transpiration and atmospheric circulation. This is a clear indication that the region is particularly vulnerable to ongoing widespread ecosystem transformation in the region and the surrounding basins. According to Ruiz-Vásquez et al. (2020), under scenarios that consider deforested areas of approximately $28 \%$ and $38 \%$ of the Amazon basin, terrestrial sources reduce their annual contributions to northern South America by an incredible average of 40 and $43 \%$. Likewise, Badger and Dirmeyer (2016), confirm that the rise of air masses over northern South America is inhibited with Amazon deforestation, which could also induce inhibition of precipitation over the region. Similarly, the teleconnections with the Orinoco basin reveal that the regional regime of precipitation is highly dependent on a zone in which raising cattle is one of the main economic sources since this is the predominant activity in the area, occupying more than $50 \%$ of the productive territory. The expansion of the areas dedicated to this activity is the main source of deforestation (González-González, Villegas, Clerici, \& Salazar, 2021). Overall, our results indicate the importance of the hydrological coupling of terrestrial ecosystems in Northern South America. Particularly in Colombia, rainfed agriculture and hydropower generation are an important proportion of the nation's economy.

Overall, our results highlight an advantage of considering stable isotopes of precipitation over using only numerical modeling, given that many models can either underestimate or overestimate the amount of atmospheric moisture (Hoyos, 2017). Additionally, many atmospheric models have difficulties to represent the 
topography of the area (Inse, Poulsen, \& Ehlers, 2010). Here, this difficulty is faced by analyzing moisture transport phenomena with stable isotopes in precipitation, precisely due to the inverse correlation between the amount of isotopic composition and altitude (Dansgaard, 1964; Rozanski et al., 1993; Mook, 2002) The simultaneous application of both techniques (physical tracer and atmospheric modeling) results in a better interpretation of the transport of atmospheric moisture. The integration of stable isotopes of precipitation and the spatial-temporal modeling can be an accurate tool that reduces the uncertainty associated with the understanding of the climate system and provides information for foreseeing possible changes in hydroclimatic patterns provenience from sources region (Risi, Bony, Vimeux, \& Jouzel, 2010; Sánchez-Murillo et al., 2013; Hu \& Dominguez, 2015).

In summary, most studies have focused on atmospheric moisture from oceanic sources (Rueda \& Poveda, 2006; Sakamoto et al., 2011; Arias et al., 2015; Yepes, Poveda, Mejía, Moreno, \& Rueda, 2019) and although a few show the importance of terrestrial sources (Kumar et al., 2016; Hoyos, 2017; Hoyos et al 2018; Molina et al., 2019; Ruiz-Vásquez, Arias, Martínez, \& Espinoza, 2020). Our results illustrate the influence of moisture recycling in two important areas of Colombia, with the largest population in the country, and whose economy and ecosystems vitally depend on water availability for ensuring moisture security. Regional atmospheric moisture composition largely controls ecosystem structure, increasing the vulnerability to climate and environmental change in the study area. Further, these natural systems are directly threatened by human activities such as deforestation and intensive agriculture, altering the exchange of water in the landatmospheric interactions, the energy balance, evapotranspiration, and therefore, the atmospheric moisture content and transport.

\section{CONCLUSIONS}

In this work, we developed a description of the atmospheric moisture sources that define rain over the Caribbean and Andean subregions in Colombia. This contribution integrates relevant information from the isotopic composition of precipitation with results from the mathematical modeling FLEXPART to better describe the structure of the regional moisture sources and the relative contribution in terms of amount and ecological relevance. This approach refines the strategy of moisture accounting by considering the optimal transport day instead of the canonical 10-day mean lifetime of water vapor in the atmosphere, avoiding, as much as possible (under)overestimations in the moisture contributions. In this sense, our calculations are more realistic and robust.

The differentiation between regions in the country allowed us to identify a variation in the amount and seasonality of moisture contribution from different sources. Our results indicate a predominance of terrestrial moisture sources (56\% and 59\% annual mean contributions for the Caribbean and Andes regions, respectively), followed by oceanic moisture sources, dominated by the contribution from the Pacific in the Andean Region (26\% contribution) and the Atlantic in the Caribbean region (28\%).

The quantification of moisture sources in each region reveals that precipitation regimes depend on the seasonality of the regional composition of moisture sources and the diverse underlying mechanisms, and the physical variables related to each zone, including variables such as topography, geographic location, and environmental features. The isotopic analysis results reveal that the processes which give origin to precipitation in the Andean region are linked to the advance of moisture flow into the continent, and are related to orographic ascent, as can be seen in the LMWLs. For the Caribbean region, the closeness factor to the main sources such as the Caribbean Sea and the Atlantic Ocean has a high influence on the precipitation regime. However, an important influence from the Pacific Ocean is also evident for this region.

The teleconnections between the sources and targets clarify that water resources management should consider not only surface hydrology, but also the links that directly influence the precipitation regime. The dynamics of the climate system at the local level is conditioned by phenomena that depend synergistically on other places, involving the transfer of vital ecosystem services. In this work, in particular, we found that the precipitation regime of the Colombian Andes is highly conditioned by meteorological and ecological processes within the region, as well as in neighboring Amazon and the Orinoco, such that ecological alterations associated with 
deforestation or land use could have impacts on the amount of moisture that is transported from these regions, threatening water, energy and economic security in the region.

\section{ACKNOWLEDGEMENTS}

Maritza Escobar was funded through the postgraduate scholarship program at Universidad de Antioquia. We thank the EPhysLab (University of Vigo) where the FLEXPART experiment was developed.

\section{DATA AVAILABILITY}

All data in this paper is available upon request to the corresponding author

\section{REFERENCES}

Aemisegger F, Pfahl S, Sodemann H, Lehner I, Seneviratne S, Wernli H. 2014. Deuterium excess as a proxy for continental moisture recycling and plant transpiration. Atmospheric Chemistry and Physics, 14(8), 40294054 .

Aggarwal PK, Froehlich KF, Gat JR. 2005. Isotopes in the water cycle. International Atomic Energy Agency (IAEA).

Alexandre P. 2020. Stable Isotopes and the Hydrosphere. In Isotopes and the Natural Environment (pp. 21-28). Springer, Cham.

Álvarez-Villa OD, Vélez JI, Poveda G. 2011. Improved long-term mean annual rainfall fields for Colombia. International Journal of Climatology, 31(14), 2194-2212.

Arias PA, Martínez JA, Vieira SC. 2015. Moisture sources to the 2010-2012 anomalous wet season in northern South America. Climate Dynamics, 45(9), 2861-2884.

Badger AM, Dirmeyer PA. 2016 Remote tropical and subtropical responses to Amazon deforestation. Climate Dynamics, 46(9-10):3057-3066.

Bax V, Francesconi W. 2019. Conservation gaps and priorities in the Tropical Andes biodiversity hotspot: Implications for the expansion of protected areas. Journal of Environmental Management, 232, 387-396.

Benjamin L, Knobel LL, Hall Lf, Cecil Ld, Green JR, and others. 2005. Development of a local meteoric water line for southeastern Idaho, western Wyoming, and south-central Montana.

Bowen GJ, Kennedy CD, Liu Z, Stalker J. 2011. Water balance model for mean annual hydrogen and oxygen isotope distributions in surface waters of the contiguous United States. Journal of Geophysical Research: Biogeosciences, 116(G4).

Bowen GJ, Ehleringer JR, Chesson LA, Stange E, Cerling TE. 2007. Stable isotope ratios of tap water in the contiguous United States. Water Resources Research, 43(3).

Bowen GJ, Revenaugh J. 2003. Interpolating the isotopic composition of modern meteoric precipitation. Water Resources Research, 39(10).

Bruijnzeel LA, Scatena FN, Hamilton LS. 2011. Tropical montane cloud forests: science for conservation and management. Cambridge University Press.

Cárdenas SG, Arias PA, Vieira SC. 2017. The African Easterly Waves over Northern South America. Multidisciplinary Digital Publishing Institute Proceedings, 1(5), 165.

Churchill SP. 2009. Moss diversity and endemism of the tropical andes1. Annals of the Missouri Botanical Garden, 96(3), 434-449.

Clark, Ian D, Fritz P. 2013. Environmental isotopes in hydrogeology. CRC press.

Clark ID, Fritz P. 1999. Environmental isotopes in hydrogeology, 2nd print, corr. Lewis Publishers, Boca Raton, USA. 
Craig H. 1961. Isotopic variations in meteoric waters. Science, 133(3465), 1702-1703.

Dansgaard W. 1964. Stable isotopes in precipitation. Tellus, 16(4), 436-468.

Díaz LB, Saurral RI, Vera CS. 2020. Assessment of South America summer rainfall climatology and trends in a set of global climate models large ensembles. International Journal of Climatology, 41(S1). https://doi.org/10.1002/joc.6643.

Durán-Quesada AM, Gimeno L, Amador JA, Nieto R. 2010. Moisture sources for Central America: Identification of moisture sources using a Lagrangian analysis technique. Journal of Geophysical Research: Atmospheres, 115(D5).

Ehrendorfer F. 2013. Woody Plants-Evolution and Distribution Since the Tertiary: Proceedings of a Symposium Organized by Deutsche Akademie der Naturforscher Leopoldina in Halle/Saale, German Democratic Republic, October 9-11, 1986 (Vol. 162, Issues 1-4). Springer Science \& Business Media.

Espinoza JC, Garreaud R, Poveda G, Arias PA, Molina-Carpio J, Masiokas M, Viale M, Scaff L. 2020. Hydroclimate of the Andes Part I: Main climatic features. Frontiers in Earth Science, 8, 64.

Friedman I, Smith GI, Gleason JD, Warden A, Harris JM. 1992. Stable isotope composition of waters in Southeastern California 1. Modern precipitation. Journal of Geophysical Research: Atmospheres, 97(D5), $5795-5812$.

Frits P, Drimmie RJ, Frape SK, Oshea K. 1987. The isotopic composition of precipitation and groundwater in Canada. In Isotope techniques in water resources development.

Froehlich K, Gibson JJ, Aggarwal PK. 2002. Deuterium excess in precipitation and its climatological significance.

Froehlich, Klaus, Kralik M, Papesch W, Rank D, Scheifinger H, Stichler, W. 2008. Deuterium excess in precipitation of Alpine regions - Moisture recycling. Isotopes in Environmental and Health Studies, 44(1), 61-70. https://doi.org/10.1080/10256010801887208.

Fuka DR, Walter MT, MacAlister C, Degaetano AT, Steenhuis TS, Easton ZM. 2014. Using the Climate Forecast System Reanalysis as weather input data for watershed models. Hydrological Processes, 28(22), $5613-5623$.

Gain AK, Hossain MS, Benson D, di Baldassarre G, Giupponi C, Huq N. 2020. Social-ecological system approaches for water resources management. International Journal of Sustainable Development \& World Ecology, 1-16.

Gat Joel R. 1996. Oxygen and hydrogen isotopes in the hydrologic cycle. Annual Review of Earth and Planetary Sciences, 24(1), 225-262.

Gat, Joel R, Bowser CJ, Kendall C. 1994. The contribution of evaporation from the Great Lakes to the continental atmosphere: estimate based on stable isotope data. Geophysical Research Letters, 21(7), 557560.

Gat JR, Matsui E. 1991. Atmospheric water balance in the Amazon Basin: an isotopic evapotranspiration model. Journal of Geophysical Research: Atmospheres, 96(D7), 13179-13188.

Gat JR, Gonfiantini R. 1981. Stable isotope hydrology. Deuterium and oxygen-18 in the water cycle. 1981. 13(13677657).

Gat JR, Carmi I. 1970. Evolution of the Isotopic Composition of Atmospheric. 75(15), 3039-3048.

Giannini A, Kushnir Y, Cane MA. 2000. Interannual variability of Caribbean rainfall, ENSO, and the Atlantic Ocean. Journal of Climate, 13(2), 297-311. 
Gimeno L, Eiras-Barca J, Durán-Quesada AM, Dominguez F, van der Ent R, Sodemann H, Sánchez-Murillo R, Nieto R, Kirchner JW. 2021. The residence time of water vapour in the atmosphere. Nature Reviews Earth \& Environment, 2(8), 558-569.https://doi.org/10.1038/s43017-021-00181-9.

Gimeno L, Nieto R, Drumond A, Castillo R, Trigo R. 2013. Influence of the intensification of the major oceanic moisture sources on continental precipitation. Geophysical Research Letters, 40(7), 1443-1450. https://doi.org/10.1002/grl.50338.

Gimeno L, Stohl A, Trigo RM, Dominguez F, Yoshimura K, Yu L, Drumond A, Durán-quesada AM, Nieto R. 2012. Oceanic and terrestrial sources of continental precipitation. 1-41. https://doi.org/10.1029/2012RG000389.

Gimeno L, Drumond A, Nieto R, Trigo RM, Stohl A. 2010. On the origin of continental precipitation. Geophysical Research Letters, 37(13).

González-González A, Villegas JC, Clerici N, Salazar JF. 2021. Spatial-temporal dynamics of deforestation and its drivers indicate need for locally-adapted environmental governance in Colombia. Ecological Indicators, 126, 107695.https://doi.org/10.1016/j.ecolind.2021.107695.

Guan H, Zhang X, Skrzypek G, Sun Z, Xu X. 2013. Deuterium excess variations of rainfall events in a coastal area of South Australia and its relationship with synoptic weather systems and atmospheric moisture sources. Journal of Geophysical Research: Atmospheres, 118(2), 1123-1138.

Herzog SK, Kattan GH. 2011. Patterns of diversity and endemism in the birds of the tropical Andes. Climate Change and Biodiversity in the Tropical Andes. Paris: McArthur Foundation, Inter-American Institute for Global Change Research (IAI) and Scientific Committee on Problems of the Environment (SCOPE), 245-259.

Hoorn C, Perrigo A, Antonelli A. 2018. Mountains, climate and biodiversity. John Wiley \& Sons.

Hoyos I, Rodríguez BA. 2020. Drawing the complexity of Colombian climate from non-extensive extreme behavior. Physica A: Statistical Mechanics and Its Applications, 548, 123673.

Hoyos I, Domínguez F, Cañón-Barriga J, Martínez JA, Nieto R, Gimeno L, Dirmeyer PA. 2018. Moisture origin and transport processes in Colombia, northern South America. Climate Dynamics, 50(3-4), 971-990. https://doi.org/10.1007/s00382-017-3653-6

Hoyos I. 2017. Transporte de humedad atmosférica en Colombia: origen, variabilidad y acople con fenómenos climáticos globales.

Hoyos I, Baquero-Bernal A, Hagemann S. 2013. How accurately are climatological characteristics and surface water and energy balances represented for the Colombian Caribbean Catchment Basin?. Climate Dynamics, 41(5-6), 1269-1290.

Hu H, Dominguez F. 2015. Evaluation of oceanic and terrestrial sources of moisture for the North American monsoon using numerical models and precipitation stable isotopes. Journal of Hydrometeorology, 16(1), $19-35$.

Hutter CR, Lambert SM, Wiens JJ. 2017. Rapid diversification and time explain amphibian richness at different scales in the Tropical Andes, Earth's most biodiverse hotspot. The American Naturalist, 190(6), $828-843$.

Insel N, Poulsen CJ, Ehlers TA. 2010. Influence of the Andes Mountains on South American moisture transport, convection, and precipitation. Climate Dynamics, 35(7-8), 1477-1492.

International Atomic Energy Agency/World Meteorological Organization. 2020. Global Network of Isotopes in Precipitation: The GNIP Database,https://www.iaea.org/services/networks/gnip

Kendall C, Coplen, T. B. 2001. Distribution of oxygen-18 and deuterium in river waters across the United States. Hydrological Processes, 15(7), 1363-1393. 
Liu B, Tan X, Gan TY, Chen X, Lin K, Lu M, Liu Z. 2020a. Global atmospheric moisture transport associated with precipitation extremes: Mechanisms and climate change impacts. Wiley Interdisciplinary Reviews: Water, 7(2), e1412.

Liu B, Tan X, Gan TY, Chen X, Lin K, Lu M, Liu Z. 2020b. Global atmospheric moisture transport associated with precipitation extremes: Mechanisms and climate change impacts. Wiley Interdisciplinary Reviews: Water, 7(2), e1412.

Martinez JA, Dominguez F. 2014. Sources of Atmospheric Moisture for the La Plata River Basin. Journal of Climate, 27(17), 6737-6753. https://doi.org/10.1175/jcli-d-14-00022.1.

Martinelli LA, Victoria RL, Sternberg LSL, Ribeiro A, Moreira MZ. 1996. Using stable isotopes to determine sources of evaporated water to the atmosphere in the Amazon basin. Journal of Hydrology, 183(3-4), 191204.https://doi.org/10.1016/0022-1694(95)02974-5

Mesa O, Urrea V, Ochoa A. 2021. Trends of Hydroclimatic Intensity in Colombia. Climate, 9(7), 120. https://doi.org/10.3390/cli9070120

Molina RD, Salazar JF, Martínez JA, Villegas JC, Arias PA. 2019. Forest-induced exponential growth of precipitation along climatological wind streamlines over the Amazon. Journal of Geophysical Research: Atmospheres, 124(5), 2589-2599.

Mook WG. 2002. Isótopos ambientales en el ciclo hidrológico (Vol. 1). IGME.

Myers N, Mittermeier RA, Mittermeier CG, da Fonseca GAB, Kent J. 2000. Biodiversity hotspots for conservation priorities. Nature, 403(6772), 853-858.

Négrel P, Petelet-Giraud E, Millot R. 2016. Tracing water cycle in regulated basin using stable $\delta^{18} \mathrm{O}-\delta^{2} \mathrm{H}$ isotopes: The Ebro river basin (Spain). Chemical Geology, 422, 71-81.

Newman BD, Wilcox BP, Archer SR, Breshears DD, Dahm CN, Duffy CJ, McDowell NG, Phillips FM, Scanlon BR, Vivoni ER. 2006. Ecohydrology of water-limited environments: A scientific vision. Water Resources Research, 42(6).

Nieto R, Gimeno L. 2019. A database of optimal integration times for Lagrangian studies of atmospheric moisture sources and sinks. Scientific Data, 6(1).https://doi.org/10.1038/s41597-019-0068-8

Numaguti A. 1999. Origin and recycling processes of precipitating water over the Eurasian continent: Experiments using an atmospheric general circulation model. Journal of Geophysical Research: Atmospheres, 104(D2), 1957-1972.

Petit JR, White JWC, Young NW, Jouzel J, Korotkevich YS. 1991. Deuterium Excess in Recent Antarctic Snow values. Journal of Geophysical Research, 96, 5113-5122.

Poveda G, Jaramillo L, Vallejo LF. 2014. Seasonal precipitation patterns along pathways of South American low-level jets and aerial rivers. Water Resources Research, 50(1), 98-118.

Poveda G, Waylen PR, Pulwarty RS. 2006. Annual and inter-annual variability of the present climate in northern South America and southern Mesoamerica. Palaeogeography, Palaeoclimatology, Palaeoecology, 234(1), 3-27.

Pringle CM. 2001. Hydrologic Connectivity and the Management of Biological Reserves: A Global Perspective Author (s): Catherine M. Pringle Hydrologic connectivity and the management of biological reserves: a global perspective. Ecological Applications, 11(August), 981-998.

Putman AL, Fiorella RP, Bowen GJ, Cai Z. 2019. A Global Perspective on Local Meteoric Water Lines: Meta-analytic Insight Into Fundamental Controls and Practical Constraints. Water Resources Research, 55(8), 6896-6910. https://doi.org/10.1029/2019WR025181. 
Rindsberger M, Jaffe S, Rahamim S, Gat JR. 1990. Patterns of the isotopic composition of precipitation in time and space: data from the Israeli storm water collection program. Tellus B, 42(3), 263-271.

Rindsberger M, Magaritz M, Carmi I, Gilad D. 1983. The relation between air mass trajectories and the water isotope composition of rain in the Mediterranean Sea area. Geophysical Research Letters, 10(1), 43-46.

Risi C, Bony S, Vimeux F, Jouzel J. 2010. Water-stable isotopes in the LMDZ4 general circulation model: Model evaluation for present-day and past climates and applications to climatic interpretations of tropical isotopic records. Journal of Geophysical Research: Atmospheres, 115(D12).

Rivadeneira Vera JF. 2020. Impacto del cambio climático en la seguridad alimentaria de climas tropicales. Aplicación a la Demarcación Hidrográfica de Manabí-Ecuador.

Rozanski K, Araguás-Araguás L, Gonfiantini R. 1993. Isotopic patterns in modern global precipitation. GMS, $78,1-36$.

Rueda OA, Poveda G. 2006. Spatial and temporal variability of the Choco jet stream and its effect on the hydroclimatology of the Colombian pacific. Meteorologia Colombiana, (10), 132-145.

Ruiz-Vásquez M, Arias PA, Martínez JA, Espinoza JC. 2020. Effects of Amazon basin deforestation on regional atmospheric circulation and water vapor transport towards tropical South America. Climate Dynamics, 54(9), 4169-4189.

Sakamoto MS. 2011. Moisture Sources and Life Cycle of Convective Systems over Western Colombia. 2011. https://doi.org/10.1155/2011/890759

Salati E, Dall'Olio A, Matsui, E, Gat JR. 1979. Recycling of water in the Amazon basin: an isotopic study. Water Resources Research, 15(5), 1250-1258.

Sánchez-Murillo R, Birkel C, Welsh K, Esquivel-Hernández G, Corrales-Salazar J, Boll J, Brooks E, Roupsard O, Sáenz-Rosales O, Katchan I, and others. 2016. Key drivers controlling stable isotope variations in daily precipitation of Costa Rica: Caribbean Sea versus Eastern Pacific Ocean moisture sources. Quaternary Science Reviews, 131, 250-261.

Sánchez Murillo R, Esquivel Hernández G, Welsh KS, Brooks E, Boll J, Alfaro Solís R, Valdés González J. 2013. Spatial and temporal variation of stable isotopes in precipitation across Costa Rica: an analysis of historic GNIP records.

Simpson HJ, Herczeg AL. 1991. Stable isotopes as an indicator of evaporation in the River Murray, Australia. Water Resources Research, 27(8), 1925-1935.

Sodemann H, Lai TM, Marenco, F, Ryder CL, Flamant C, Knippertz P, Rosenberg P, Bart M, McQuaid JB. 2015. Lagrangian dust model simulations for a case of moist convective dust emission and transport in the western Sahara region during Fennec/LADUNEX. Journal of Geophysical Research: Atmospheres, 120(12), 6117-6144. https://doi.org/10.1002/2015jd023283

Snow JW. 1975. The Climates of Northern South America. University of Wisconsin-Madison.

Stohl, A, James P. 2005. A Lagrangian analysis of the atmospheric branch of the global water cycle. Part II: Moisture transports between Earth's ocean basins and river catchments. Journal of Hydrometeorology, 6(6), 961-984.

Stohl A, James P. 2004. A Lagrangian Analysis of the Atmospheric Branch of the Global Water Cycle. Part I: Method Description, Validation, and Demonstration for the August 2002 Flooding in Central Europe. Journal of Hydrometeorology, 5(4), 656-678.

Swann ALS, Longo M, Knox RG, Lee E, Moorcroft PR. 2015. Future deforestation in the Amazon and consequences for South American climate. Agricultural and Forest Meteorology, 214-215, 1224.https://doi.org/10.1016/j.agrformet.2015.07.006. 
Terzer-Wassmuth S, Wassenaar LI, Welker JM, Araguas-Araguas LJ. 2021. Improved high-resolution global and regionalized isoscapes of $\delta^{18} \mathrm{O}, \delta^{2} \mathrm{H}$ and d-excess in precipitation. Hydrological Processes, 35(6).https://doi.org/10.1002/hyp.14254.

Van der Ent RJ, Tuinenburg OA. 2017. The residence time of water in the atmosphere revisited. Hydrology and Earth System Sciences, 21(2), 779-790. https://doi.org/10.5194/hess-21-779-2017.

Van der Ent RJ, Savenije HHG, Schaefli B, Steele-Dunne SC. 2010. Origin and fate of atmospheric moisture over continents. Water Resources Research, 46(9).

Wagener T, Sivapalan M, Troch PA, McGlynn BL, Harman CJ, Gupta H, Kumar P, Rao PSC, Basu NB, Wilson JS. 2010. The future of hydrology: An evolving science for a changing world. Water Resources Research, 46(5).

Wang Y, Leung LR, McGREGOR JL, Lee DK, Wang WC, Ding Y, Kimura F. 2004. Regional climate modeling: progress, challenges, and prospects. Journal of the Meteorological Society of Japan. Ser. II, 82(6), 1599-1628.

Yepes J, Poveda G, Mejía JF, Moreno L, Rueda C. 2019. Choco-jex: A research experiment focused on the Chocó low-level jet over the far eastern Pacific and western Colombia. Bulletin of the American Meteorological Society, 100(5), 779-796.

Yurtsever Y. 1981. Atmospheric waters. Stable Isotope Hydrology: Deuterium and Oxygen-18 in Water Cycle.

\section{FIGURE LEGENDS}

FIGURE 1. Study area. Regional orography (m) from Global Land One-kilometer Base Elevation (GLOBE, (Hastings and Dunbar 1998)). Andean and Caribbean regions, in yellow and green respectively. GNIP Stations highlighted in dark blue dots.

FIGURE 2. Regional source of atmospheric moisture considered in the experimental setting for the FLEXPART model. We adopt source regions and names as [Hoyos et al., 2018]. Tropical North Pacific (TNP), Tropical South Pacific (TSP), Subtropical North Atlantic (STNA), Tropical North Atlantic (TNA), Tropical Atlantic (TA), Tropical South Atlantic (TSA), Caribbean Sea (CARS), Northern South America (NOSA, target region), Orinoco Basin (ORIC), Northern Amazon Basin (NAMZ), Southern Amazon Basin (SAMZ).

FIGURE 3: Qualitative summary of how hydrologic processes affect oxygen and hydrogen isotopic composition of rainwater. Pairs of $\delta^{18} \mathrm{O}$ and $\delta^{2} \mathrm{H}$ can be distributed along with the entire possible variation range, according to the depletion or enrichment of observations and the meteorological conditions of the atmospheric moisture sources.

FIGURE 4. Annual cycle of precipitation from observational data (black) from 1506 sampling points distributed as shown in a.) and estimations from the percentage of diagnostic precipitation accounted for FLEXPART (gray). b.) Caribbean and c.) Andean regions.

FIGURE 5. Annual cycle of precipitation contribution from the main Atlantic (a,d), Pacific (b,e) and terrestrial (c,f) sources. Top (bottom) panels for the Andean (Caribbean) region. Precipitation amount is estimated from percentage of contributions based on diagnostic precipitation.

FIGURE 6. Seasonal summary of Oceanic (Atlantic and Pacific) and terrestrial percentages of moisture contributions to the Andean (a) and Caribbean (b) regions.

FIGURE 7. Seasonal reconstruction of LMWL and Deuterium excess. Blue dashed lines correspond to GMWL. Green (orange) lines correspond to the LMWL in the Colombian Andean (Caribbean) region. Interpolation of seasonal D-excess is shown in the box located in the upper left. 


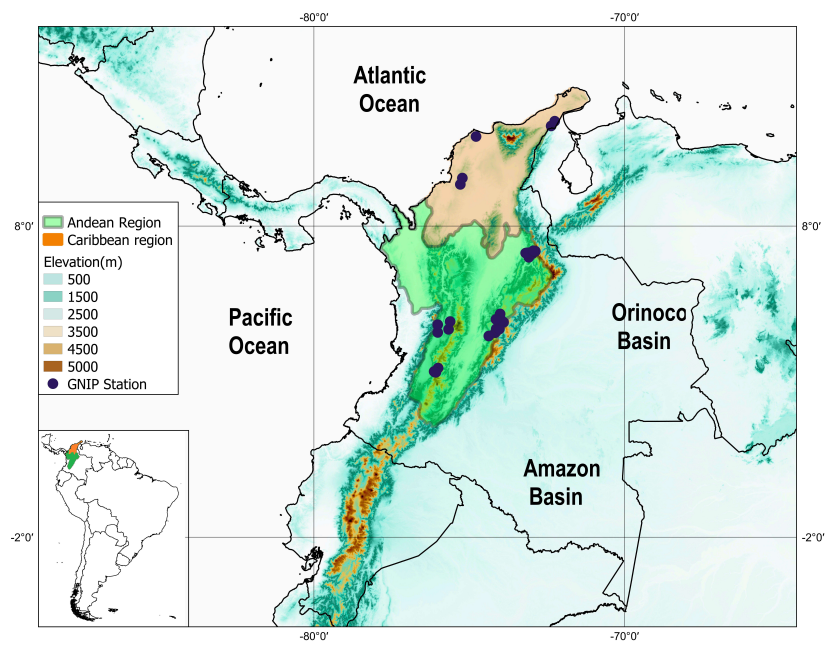

Figure 1: Study area. Regional orography (m) from Global Land One-kilometer Base Elevation (GLOBE; Hastings et al., 2000). Andean and Caribbean regions, in yellow and green respectively. GNIP Stations in dark blue dots. 


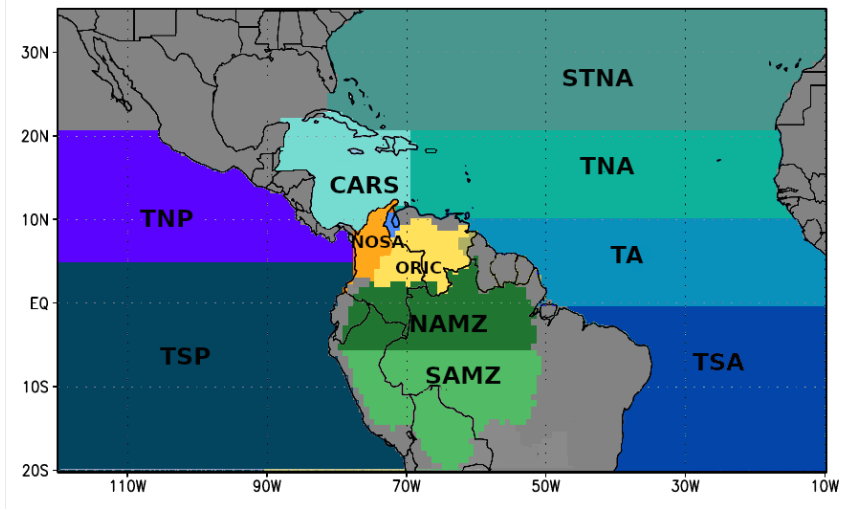

Figure 2: Regional source of atmospheric moisture considered in the experimental setting for the FLEXPART model. We adopt source regions and names as [Hoyos et al., 2018]. Tropical North Pacific (TNP), Tropical South Pacific (TSP), Subtropical North Atlantic (STNA), Tropical North Atlantic (TNA), Tropical Atlantic (TA), Tropical South Atlantic (TSA), Caribbean Sea (CARS), Northern South America (NOSA), Orinoco Basin (ORIC), Northern Amazon Basin (NAMZ), Southern Amazon Basin (SAMZ). 


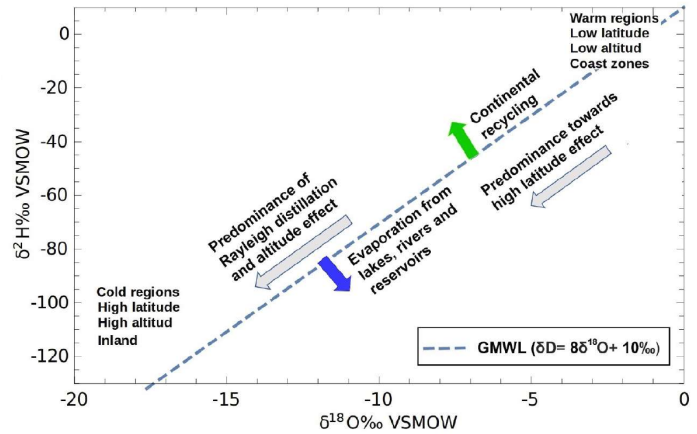

Figure 3: Qualitative summary of how hydrologic processes affect oxygen and hydrogen isotopic composition of rainwater. Pairs of $\delta^{18} O$ and $\delta^{2} H$ can be distributed along with the entire possible variation range, according to the depletion or enrichment of observations and the meteorological conditions of the atmospheric moisture sources. 

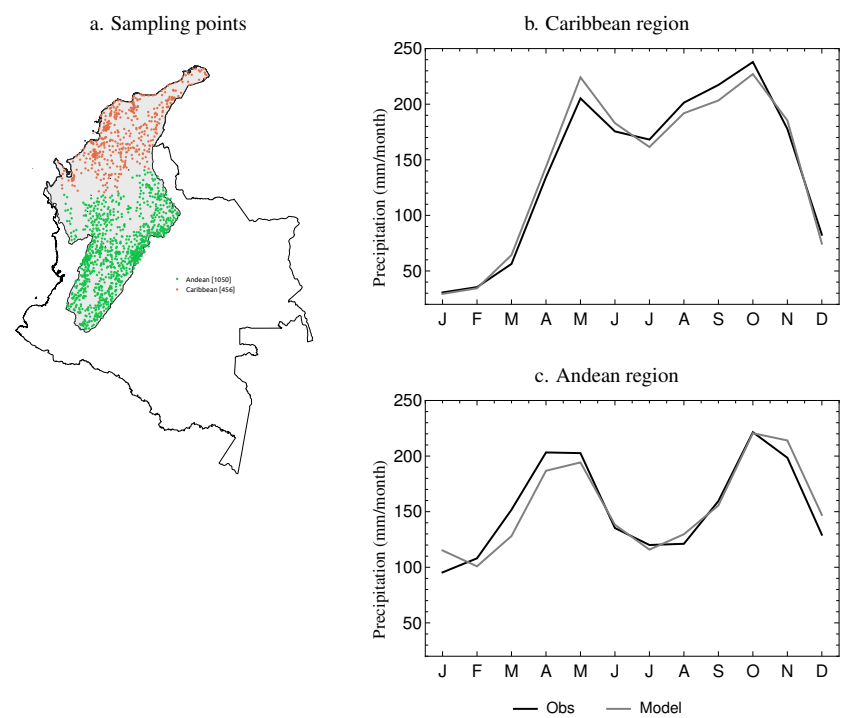

Figure 4: Annual cycle of precipitation from observational data (black) from 1506 sampling points distributed as shown in a.) and estimations from the percentage of diagnostic precipitation accounted for FLEXPART (gray). b.) Caribbean and c.) Andean regions. 

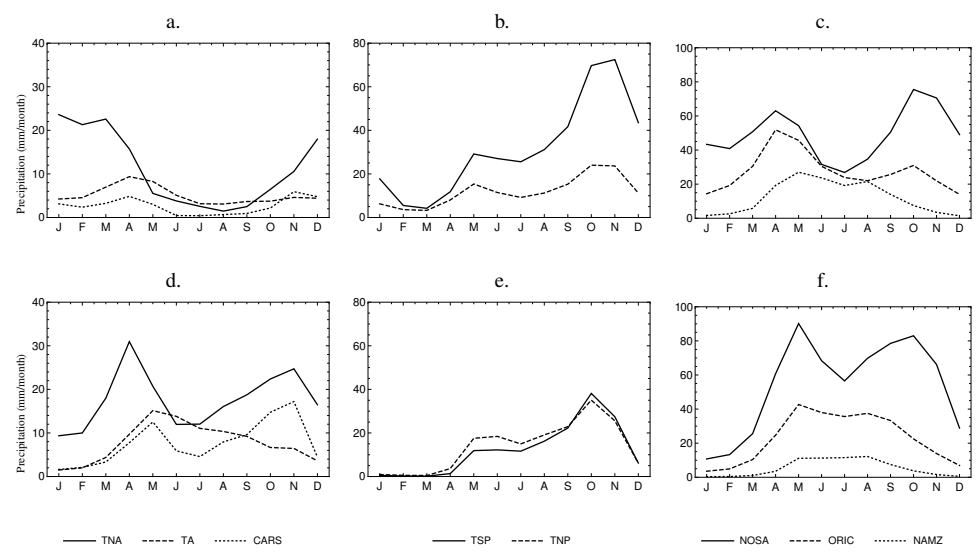

$$
\text { - TNA }
$$

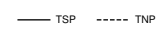

Figure 5: Annual cycle of precipitation contribution from the main Atlantic (a,d), Pacific (b,e) and terrestrial $(\mathrm{c}, \mathrm{f})$ sources. Top (bottom) panels for the Andean (Caribbean) region. Precipitation amount is estimated from percentage of contributions based on diagnostic precipitation. 


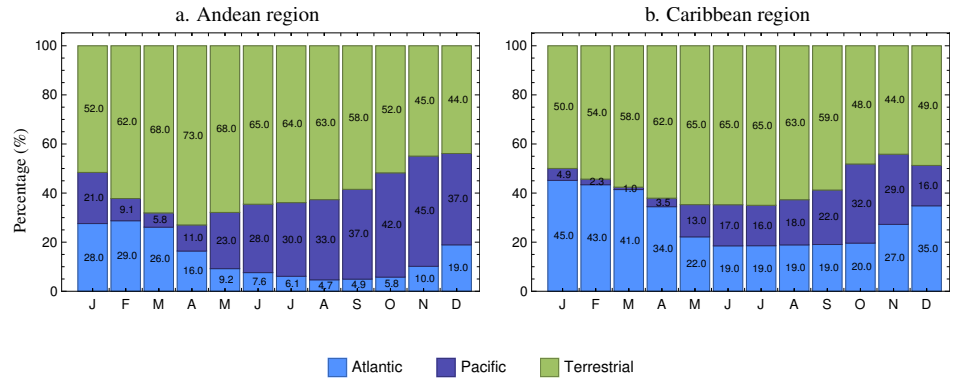

Figure 6: Seasonal summary of Oceanic (Atlantic and Pacific) and terrestrial percentages of moisture contributions to the Andean (a) and Caribbean (b) regions. 

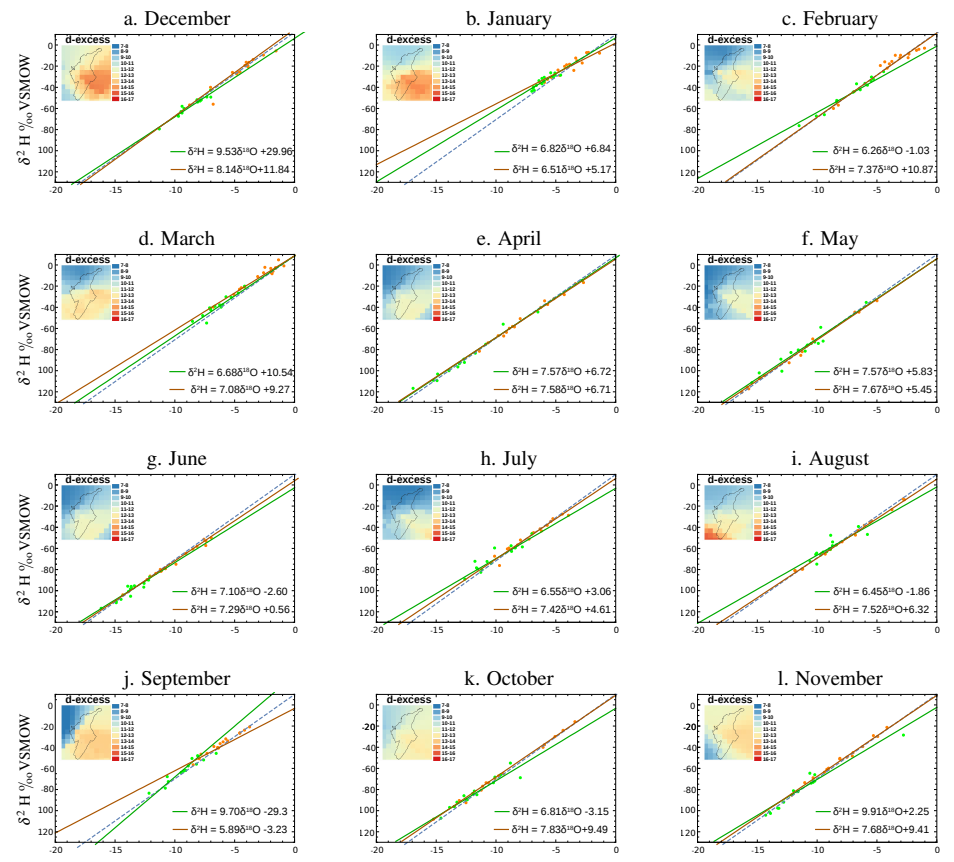

$\delta^{18} \mathrm{O} \%$ VSMOW

Figure 7: Seasonal reconstruction of LMWL and Deuterium excess. Blue dashed lines correspond to GMWL. Green (orange) lines correspond to the Colombian Andean (Caribbean) region. Interpolation of seasonal Dexcess is shown in the box located in the upper left. 
TABLE 1. Regional moisture transport scales. Time-scale is determined by the optimal transport integration day. The spatial-scale corresponds to the maximum linear distance

from the source region to the central point to the target region.

\begin{tabular}{|c|c|c|c|c|}
\hline \multirow{2}{*}{ Source } & \multicolumn{2}{|c|}{ Andean } & \multicolumn{2}{c|}{ Caribbean } \\
\cline { 2 - 5 } & Time-scale (day) & $\begin{array}{c}\text { Spatial-scale } \\
\mathbf{1 0}^{\mathbf{3}} \mathbf{~ k m}\end{array}$ & $\begin{array}{c}\text { Time-scale } \\
\text { (day) }\end{array}$ & $\begin{array}{c}\text { Spatial-scale } \\
\mathbf{1 0}^{\mathbf{3}} \mathbf{~ k m}\end{array}$ \\
\hline TNA & 10 & 6.6 & 10 & 6.3 \\
\hline TA & $10+$ & 7.3 & $10+$ & 7.2 \\
\hline TSA & $10+$ & 7.6 & $10+$ & 7.8 \\
\hline STNA & $10+$ & 7.4 & 10 & 7.1 \\
\hline CARS & $4-6$ & 2.3 & $3-4$ & 1.9 \\
\hline TSP & 2 (Jan to Apr) & 5.6 & $8-9$ & 6.0 \\
\hline TNP & 2 & 4.9 & $2-3$ & 5.2 \\
\hline NOSA & 1 & $*$ & 1 & $*$ \\
\hline ORIC & $3-4$ & 1.7 & $4-5$ & 1.4 \\
\hline NAMZ & $6-7$ & 3.0 & 8 & 3.1 \\
\hline SAMZ & 10 & 3.1 & $10+$ & 3.3 \\
\hline
\end{tabular}

\section{Hosted file}

Table_2.pdf available at https://authorea.com/users/437803/articles/539185-the-importanceof-continental-evaporation-for-precipitation-in-colombia-a-baseline-combiningobservations-from-stable-isotopes-and-modeling-moisture-trajectories

\section{Hosted file}

Table_3.pdf available at https://authorea.com/users/437803/articles/539185-the-importanceof-continental-evaporation-for-precipitation-in-colombia-a-baseline-combiningobservations-from-stable-isotopes-and-modeling-moisture-trajectories 